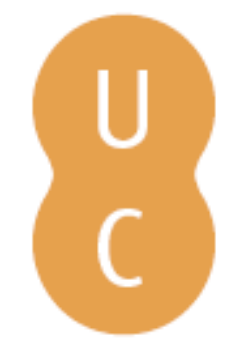

\title{
pommalina
}

\section{Entre o fim do Império e o início da Idade Média: as mudanças na estrutura do povoamento na região noroeste da Serra da Estrela (centro do Portugal)}

\author{
Autor(es): $\quad$ Tente, Catarina \\ Publicado por: Imprensa da Universidade de Coimbra \\ URL \\ persistente: URI:http://hdl.handle.net/10316.2/41860 \\ DOI: $\quad$ DOI:https://doi.org/10.14195/978-989-26-1353-6_1 \\ Accessed : $\quad$ 26-Apr-2023 02:49:22
}

A navegação consulta e descarregamento dos títulos inseridos nas Bibliotecas Digitais UC Digitalis, UC Pombalina e UC Impactum, pressupõem a aceitação plena e sem reservas dos Termos e Condições de Uso destas Bibliotecas Digitais, disponíveis em https://digitalis.uc.pt/pt-pt/termos.

Conforme exposto nos referidos Termos e Condições de Uso, o descarregamento de títulos de acesso restrito requer uma licença válida de autorização devendo o utilizador aceder ao(s) documento(s) a partir de um endereço de IP da instituição detentora da supramencionada licença.

Ao utilizador é apenas permitido o descarregamento para uso pessoal, pelo que o emprego do(s) título(s) descarregado(s) para outro fim, designadamente comercial, carece de autorização do respetivo autor ou editor da obra.

Na medida em que todas as obras da UC Digitalis se encontram protegidas pelo Código do Direito de Autor e Direitos Conexos e demais legislação aplicável, toda a cópia, parcial ou total, deste documento, nos casos em que é legalmente admitida, deverá conter ou fazer-se acompanhar por este aviso.

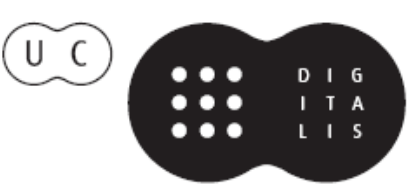




\section{Arqueologia \\ da transição:}

entre o mundo romano

e a Idade Média

Cláudia Teixeira, André Carneiro (coords.)

IMPRENSA DA UNIVERSIDADE DE COIMBRA

ANNABLUME 


\title{
ENTRE O Fim do IMPÉRIO E O INÍCIO da IdAdE MÉdia: AS MUDANÇAS NA ESTRUTURA DO POVOAMENTO NA REGIÃO NOROESTE da Serra da Estrela (centro do Portugal) (Between the end of Empire and the beginning of the Middle Ages: changes in the rural settlement in the northwest area of the Serra da Estrela (center Portugal))
}

\author{
Catarina Tente (catarina.tente@gmail.com)
} IEM/FCSH-UNL

\begin{abstract}
Resumo - O presente estudo procura analisar as estratégias e a organização do povoamento na encosta Noroeste da Serra da Estrela após o colapso do Império romano. O abandono de estruturas e núcleos de povoamento entre o $4 .^{\circ}$ e o $5 .^{\circ}$ século foi revelado por escavações arqueológicas, e a rede de povoamento resultante é pouco visível, com as evidências apontando para uma fragmentação ou desaparecimento das civitates romanas. O processo é acompanhado pelo surgimento de novas elites que dominam areas mais restritas. Entre o século $8 .^{\circ}$ e o $9 .^{\circ}$ novas mudanças ocorrem: locais ocupados por elites, como o Castro do Tintinolho, são abandonado, e pontos de povoamento são fundados em zonas baixas, embora com reforço de sistemas defensivos.

Palavras chave - território, mudanças sociais, estruturas rurais, civitates, Alta Idade Média, castellum, vilas.
\end{abstract}

Aвstract - This work aims to address the strategies and organization of settlement after the collapse of the Roman Empire in the Northwest slope of the Serra da Estrela. The archaeological research has revealed the abandon of Roman structures during the $4^{\text {th }}$ and $5^{\text {th }}$ century. The settlement that emerges after that is still not very visible, but there are some archaeological data pointing to a fragmentation or disappearance of the ancient Roman civitates. This process is accompanied by the emergence of a new ruling class focused on smaller areas. In the $8^{\text {th }}$ and $9^{\text {th }}$ centuries new change occurred in settlement strategies. Elite's places as Castro do Tintinolho were abandoned and new villages emerge in the valleys, although endowed with defensive systems.

KEYwords - territory, social changes, rural structures, civitates, early middle ages, castellum, village

\section{O. O Alto Mondego}

Quando o poder de Roma desaparece, quem o substitui no Alto Mondego? Ou como reagem os habitantes ao desaparecimento do Estado Romano e à emergência de outros poderes? Que consequências têm estas alterações no padrão de povoamento? Estas perguntas são de difícil resposta, mas como se verá adiante, neste momento da investigação, os indicadores documentais e arqueológicos indiciam a presença de novas elites cujo poder se estrutura e se demonstra em moldes diferentes dos que haviam marcado o mundo romano. $\mathrm{O}$ início da 
investigação realizada nos últimos anos, quer em contextos romanos tardios quer alto medievais, mais do que respostas, têm levantado mais questões que marcam os caminhos para a investigação futura.

A região definida para esta abordagem designa-se genericamente por Alto Mondego, pois é este rio, conjuntamente com a vertente noroeste da Serra da Estrela que constitui o eixo estruturador do território. A serra e o rio organizam e compartimentam a paisagem, dividindo-a entre um espaço montanhoso e uma área de altitudes mais modestas, que é denominada de "Plataforma da Beira Alta" (Ferreira, 1978), esta constitui uma das mais importantes "portas" da História portuguesa, permitindo a passagem de Norte para Sul e do interior da Meseta para o litoral ocidental, dando acesso direto a Viseu e a Coimbra. A encosta Noroeste, que domina o grande corredor da Beira Alta, apresenta-se com uma vigorosa muralha montanhosa atravessada por numerosos pequenos cursos de água, que descem a serra para desaguarem no médio Mondego. Esta vertente, notavelmente retilínea, apresenta inclinações moderadas, entre $11 .^{\circ}$ e $17 .^{\circ}(\mathrm{Da}-$ veau, 1969 , p. 40).

No que aos concelhos actuais diz respeito, a área abordada integra os da Guarda, Celorico da Beira, Fornos de Algodres e Gouveia (figura 1). Trata-se de uma área geologicamente dominada pela ocorrência de rochas graníticas com intrusões de rochas do complexo xisto-grauváquico. Os depósitos sedimentares são bastante limitados em dimensão e correspondem a dois grupos de formação: os aluviões e os depósitos arcósico-argilosos. Os aluviões são depósitos actuais que se localizam ao longo dos vales e que, na generalidade, tem reduzidas espessuras.

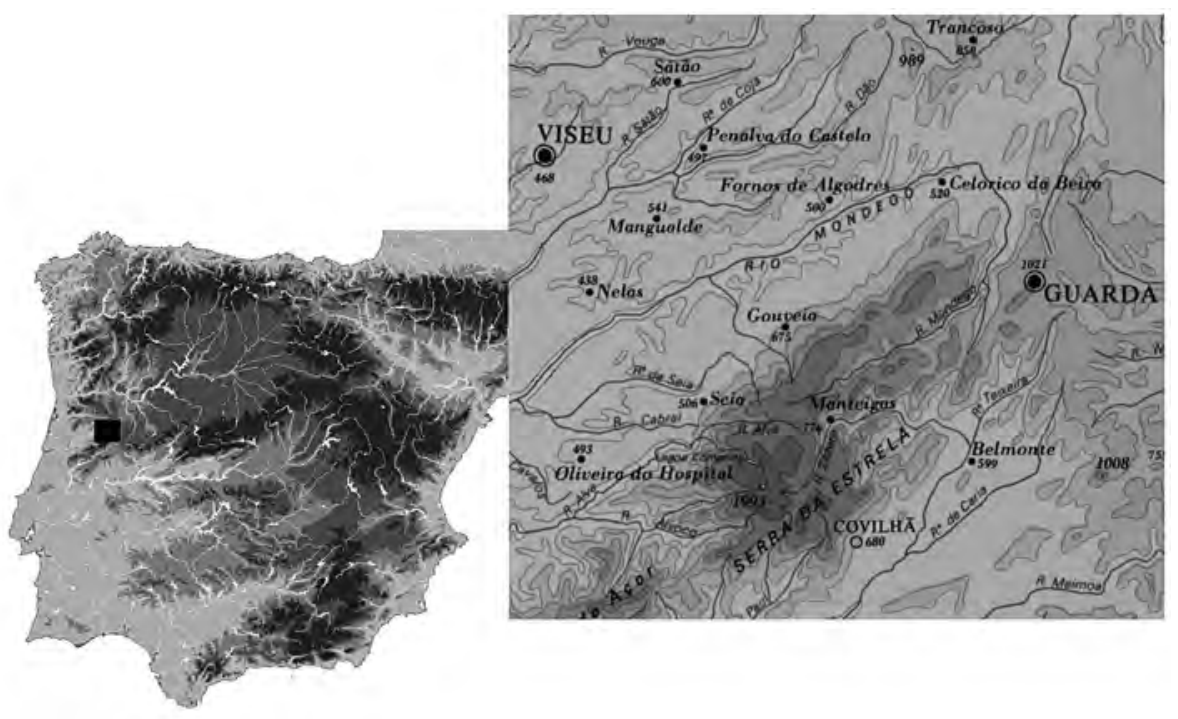

Figura 1 - Localização do Alto Mondego. 
Não obstante, foram sempre áreas preferenciais para as práticas agrícolas, tal como é o caso do Vale do Mondego entre a Ribeira do Caldeirão e a Bacia de Celorico. A vertente Noroeste da serra é ainda percorrida por inúmeros cursos de água dispostos mais ou menos paralelamente que descem a serra em direcção ao Mondego, irrigando as encostas serranas e ao planalto do vale do Mondego.

\section{Os Sítios Romanos APós o SÉculo IV}

Quando se aborda o fim do Império Romano no que se refere ao povoamento tem de se partir, naturalmente, do panorama nos séculos il e iII d.C. Aqui reside a primeira grande dificuldade. A informação disponível para o povoamento e a organização administrativa romana no Alto Mondego é ainda pouco consistente. Tal ocorre porque a maioria dos dados disponíveis advêm da prospeção essencialmente de superfície, e a interpretação que tem sido feita sobre os mesmos incorre portanto nos problemas que este tipo de informação muito parcial. Existem assim algumas abordagens interpretativas do povoamento romano avançadas por M. S. Perestrelo (2003), P. Carvalho (2007 e 2009), V. Pereira (2008) e mais recentemente por A.C. Marques (2011), que, na sua tese de mestrado aborda o povoamento romano da Bacia de Celorico. Todavia, a maioria destes trabalhos assentam fundamentalmente no trabalho de prospeção e no exercício de relacionar o tamanho das áreas de dispersão dos vestígios com os diferentes tipos de sítios rurais existentes em período romano. Apesar de ser um ponto de partida válido, este tipo de abordagem levanta muitos problemas relativamente à atribuição cronológica de cada sítio, construindo-se, por vezes, uma imagem do mundo rural romano como um espaço estático. Por outro lado desenham-se redes de povoamento lógicas, mas cujos fundamentos são pouco sólidos, por não dispor em, muitos dos casos, de dados concretos que permitam atribuir determinados vestígios a um vicus, uma civitas, uma villa, uma quinta ou um casal, etc.

Em consequência há, igualmente, muitas dúvidas quanto ao mapa administrativo romano. Não sendo claro a que civitas ou civitates estaria este território integrado. Revendo as propostas de localização destas capitais administrativas nos territórios limítrofes ao Alto Mondego sugere-se que a Noroeste localizar-se-ia a capital dos Interanienses que parece corresponder à actual cidade de Viseu (Vissaium). É possível que o seu território se estendesse até à margem direita do Mondego, o que hoje corresponde aos concelhos de Mangualde e, provavelmente, parte do de Fornos de Algodres. Na Bobadela (Oliveira do Hospital) podia situar-se a capital dos Tapori, mas esta atribuição não reúne consenso. Parte da área mais ocidental do concelho de Gouveia poderá ter estado integrada neste território. A Norte situar-se-ia a Civitas Aravorum, com sede em Marialva (Meda), que eventualmente integraria as áreas norte dos atuais concelhos de Celorico da Beira e de Fornos de Algodres. Parte, ou provavelmente a totalidade, 
da área da bacia de Celorico terá estado integrada na civitas dos Lancienses Transcudani, que se tem aventado a possibilidade de poder corresponder aos vestígios identificados na Póvoa do Mileu (Guarda), ainda que também esta atribuição não seja pacífica (Carvalho, 2005, 2009; Guerra, 2007; Marques, 2011; Pereira, 2005, 2008; Perestrelo, 2003).

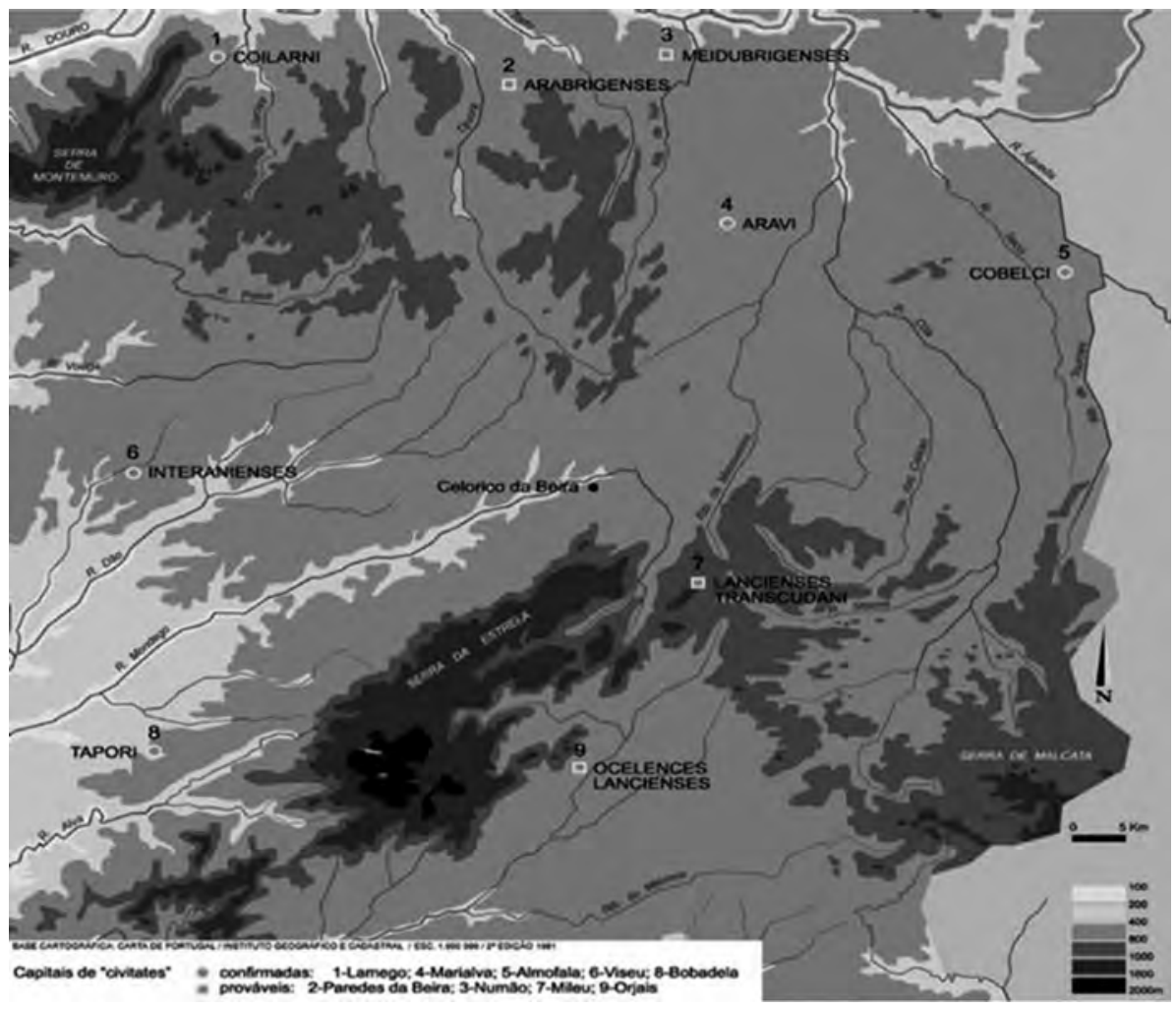

Figura 2 - Mapa das civitates da região da Beira Interior publicado por P. Carvalho, 2009, p. 36 .

Independentemente do tipo de sítio ou da dimensão que os dados de superfície possam sugerir, verifica-se que os vestígios romanos ocupam preferencialmente áreas de vales e de rechãs ricas em água. A presença da água compensa em muitos dos sítios a debilidade produtiva dos terrenos. São raros ou inexistentes os vestígios deste período nos altos planaltos serranos ou nas áreas mais pedregosas e carentes de água. É sobretudo na denominada Bacia de Celorico que se concentra a maioria dos vestígios de cronologia romana detectados à superfície.

Será também aí que se encontram dos principais vestígios arqueológicos que indiciam a importância de ocupações antigas. Caso exemplar é o da ac- 
tual aldeia de Açores (Celorico da Beira). A actual igreja da aldeia tem integrada numa parede lateral do altar uma epígrafe funerária (fig. 3) dedicada a Suinthiliuba, que terá falecido a 5 de Novembro de 666 (Barroca, 1992). Nas proximidades da igreja foi igualmente identificada, na abertura de um poço, uma ara que expressa um voto a Júpiter Óptimo Máximo em favor de Gaio Sílio Celso (Carvalho, Lobão e Marques, 2012). Em redor de toda a aldeia encontram-se vestígios de materiais de construção romanos e cerâmica comum, o que abona a favor de uma ocupação romana consistente daquele local, ainda que de limites cronológicos incertos. Este sítio tem sido avançado como podendo ser um dos fortes candidatos a capital de uma civitas desconhecida, defendida por alguns autores, que teria como território a Bacia de Celorico (Perestrelo, 2003; Carvalho, 2009; Marques, 2011). A ligação entre a ocupação romana óbvia daquele espaço e a inscrição de período visigodo é por agora difícil de estabelecer, ainda que a informação disponível relativamente à proveniência desta epígrafe funerária indique que a mesma terá sido encontrada durante a construção da igreja atual, ou seja, proviria do local onde ainda hoje se encontra. É, pois, prematuro avançar com a hipótese de neste sítio haver uma continuidade ocupacional entre o período romano e a Idade Média, pois apenas escavações arqueológicas poderiam eventualmente proporcionar esta informação. No entanto, não deixa de ser sintomático que esta aldeia, que se localiza no centro da Bacia de Celorico, ocupando uma das áreas mais férteis de toda a região, continue a ser durante a Idade Média e a época Moderna um local de destaque religioso, onde anualmente populações, vizinhas e de lugares distantes, se dirigiam para prestar homenagem a Santa Maria de Açores (Coelho e Pimenta, 2009; Neto, 2009).

Relativa importância pode ter tido igualmente a ocupação de Vale de Azares, igualmente situada na Bacia de Celorico. Ali conhecem-se vários vestígios arquitectónicos de cronologia romana e uma inscrição dedicada a Ama Aracelene, uma divindade local (Ferreira, Osório e Perestelo, 2004). Uma vez mais, identificaram-se também vestígios arqueológicos alto-medievais, tais como sarcófagos, sepulturas escavadas na rocha, cerâmica comum e um silhar decorado com círculos gomados, actualmente integrado na parede da capela de Fonte Arcada (Tente, 2007). A falta de trabalhos de investigação arqueológica e o crescimento urbano das aldeias condiciona, por agora, quaisquer interpretações acerca do papel deste local e sobre a continuidade de ocupação entre os tempos do Império Romano e a Alta Idade Média. Alexandre Herculano considera que o topónimo Azares significa "uma correria feita pelos habitantes de povoação por sua conta e risco" (Apud Machado, 1991, p. 26), ou seja refere-se a algaras. Se assim for, tanto se pode considerar como resultante de ataques surpresa vindos do exterior como ataques empreendidos pelos habitantes da região. Seja como for este topónimo de origem árabe sublinha a ocupação alto-medieval deste espaço (Tente, 2010). 


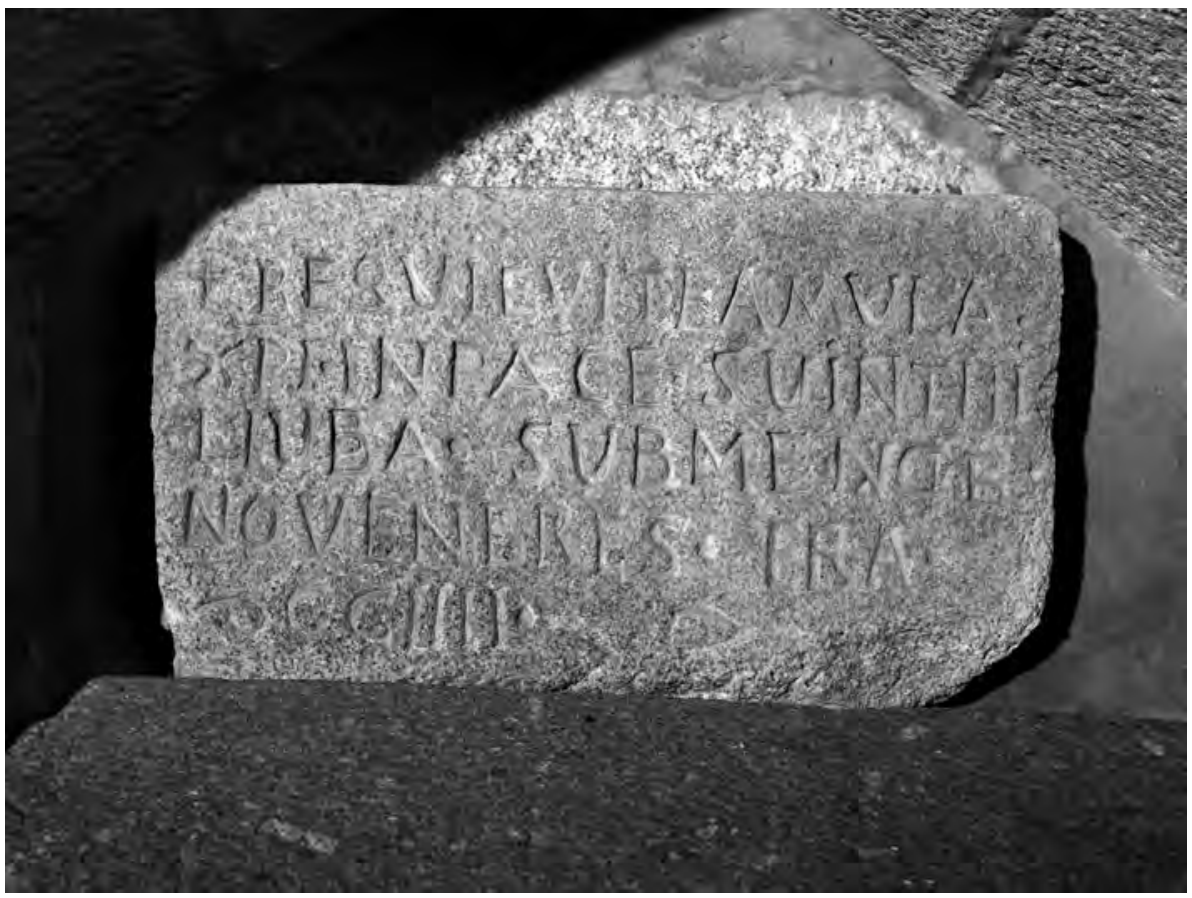

Figura 3 - Inscrição de período visigodo identificada em Santa Maria de Açores (fotografia de Danilo Pavone, (C) C. M. Celorico da Beira).

$\mathrm{Na}$ Guarda tem vindo a ser realizadas várias campanhas de escavação na Póvoa do Mileu, por V. Pereira, que têm mostrado uma importante ocupação romana, nos limites da cidade actual. A natureza destes vestígios tem levantado alguma polémica sobre a correspondência ou não deste local com a capital dos Lancienses Transcudani (Carvalho, 2008; Carvalho 2009; Pereira, 2008), povo que está representado na inscrição da Ponte de Alcântara (Alarcão, 2007). Independentemente dessa correlação, os dados disponíveis indiciam uma ocupação romana estável pelo menos até ao século III (Pereira, 2008). O aparecimento de um ponderal bizantino e de um tremis cunhado no reinado de Égica (687-702) documenta uma certa continuidade do local, ainda que os dados até agora publicados não permitem compreender que tipo de ocupação seria e se houve ou não hiatos no uso daquele espaço.

$\mathrm{Na}$ área mais ocidental do vale do Alto Mondego, no actual concelho de Gouveia, foi arqueologicamente intervencionado o sítio do Monte Aljão (Rio Torto), localizado nas proximidades da estrada que liga Gouveia a Mangualde. O mesmo é mencionado pela primeira vez numa carta de Bernardo Rodrigues do Amaral dirigida a José Leite de Vasconcelos, datada de 9 de Maio de 1904. O sítio não volta a ser mencionado até 1980, quando durante uma surriba para 
plantio de uma vinha se afectam vários contextos arqueológicos. Este episódio destrutivo motivou a intervenção arqueológica de minimização realizada pelos Serviços Regionais de Cultura da Zona Centro. O relatório então produzido dá conta da escavação de uma área de $45 \mathrm{~m}^{2}$ onde se identificam cinco níveis de ocupação, dois de cronologia romana incerta e três de cronologia medieval, entre os quais se destaca a necrópole de sepulturas escavadas no substrato rochoso. Infelizmente, o relatório da intervenção é muito simplista e insuficiente quanto aos critérios usados para a distinção entre os diversos níveis de ocupação. Por outro lado, não existe uma única linha que descreva os materiais arqueológicos identificados e destes não há informação sobre o seu paradeiro. Como mais nenhuma informação adicional relativa a este sítio foi publicada desde então, pouco mais se conhece sobre os resultados obtidos nesta intervenção. Em 2008 e 2009 a signatária efetuou escavações arqueológica neste local que documentaram o alto grau de afetação dos contextos arqueológicos efectuados por uma outra surriba posterior à escavação dos anos 80 do século xx. Permitiram ainda identificar algumas estruturas romanas e mais sepulturas alto medievais pertencentes à necrópole ali existente (fig.4) e que havia sido identificada na intervenção dos anos 80 . Os trabalhos mais recentes permitiram recuperar contextos romanos tardios, provavelmente instalações de trabalho ligadas ao tratamento de lãs, que são abandonadas dos finais do século IV ou inícios do século v (Tente, 2010; Tente e Carvalho, 2011). O começo desta ocupação é mais difícil de precisar, mas terá ocorrido por volta do século I ou II d.C. Para já, não se consegue esclarecer se este abandono foi progressivo ou se ocorreu na sequência de qualquer evento súbito. Apesar dos fenómenos pós-deposicionais destrutivos que este sítio sofreu, foi possível verificar que há efetivamente um hiato ocupacional entre este abandono e os níveis medievais, bem marcado numa camada de abandono identificada no registo estratigráfico. Neste sítio é claro que não houve qualquer continuidade ocupacional entre o século $\mathrm{V}$ e os séculos Ix/x, altura em que a necrópole parece estar em uso (Tente, 2010). Quando se retoma o local? A organização interna da necrópole indicia que houvesse ali uma igreja que, porém, não foi identificada. Talvez esta ocupação medieval do sítio tenha origem nesse edifício, mas é incerta a sua localização e cronologia de fundação. Mais certo é a cronologia do uso da necrópole que aparente estar balizada entre os século Ix/X e o século XII, altura em que Afonso Henriques vende a villa prenominata Aldiam a dois particulares (doc. 52 do Livro Preto de Santa Cruz de Coimbra, Ventura e Faria, 1990, p. 184). 


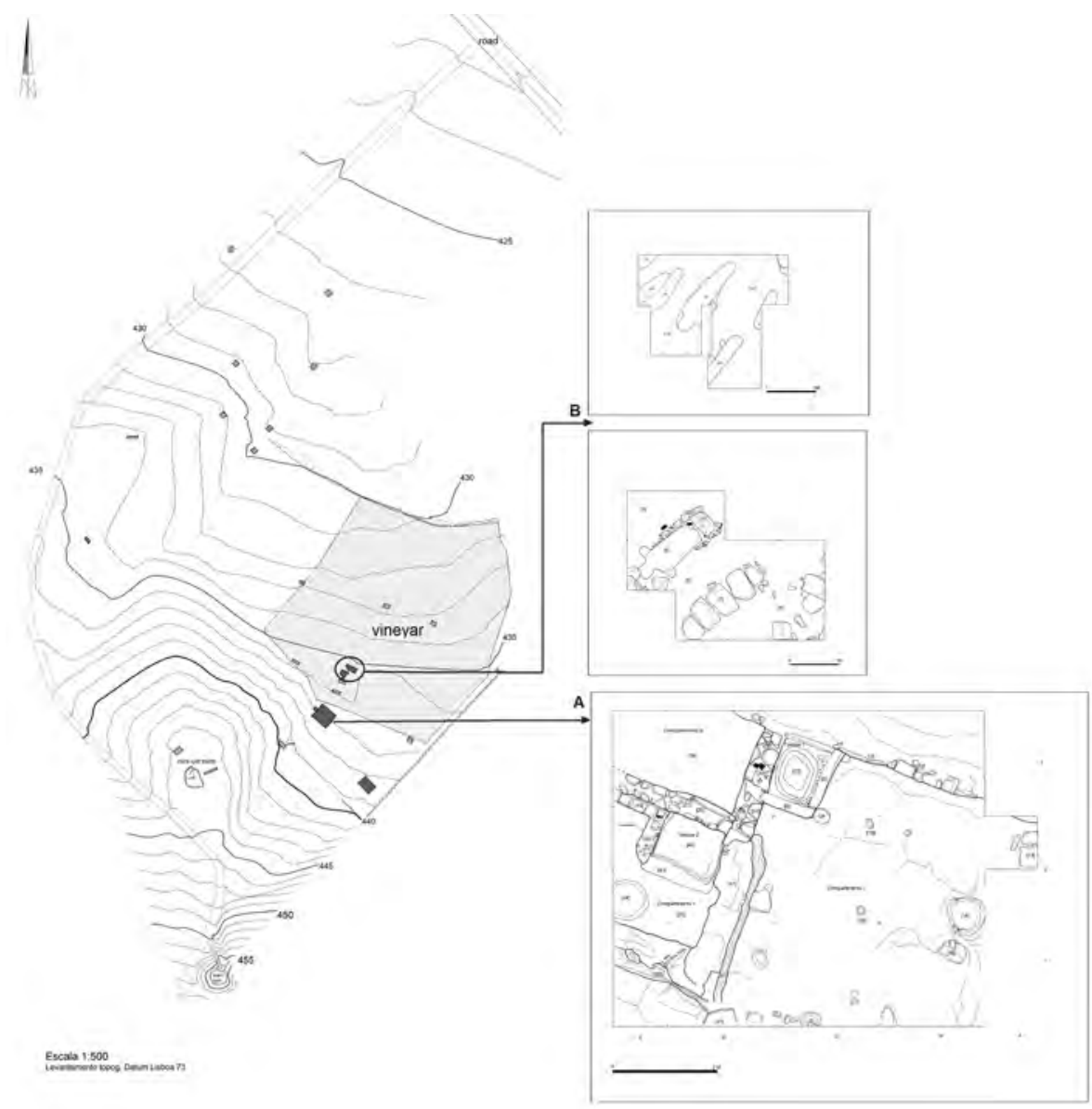

Figura 4 - Levantamento topográfico do sítio arqueológico do Monte Aljão (Rio Torto, Gouveia): A - Contextos de tanques cujo abandono está datado do final século iv e início do século v; B - Necrópole alto medieval de sepulturas escavadas no substrato rochoso provavelmente em uso durante o século x (Tente, 2010).

Em S. Gens (Forno Telheiro, Celorico da Beira), as escavações do sector 9, levadas a cabo por A. Marques, arqueólogo do município de Celorico da Beira, identificaram um edifício com vários compartimentos, que foi interpretado como uma habitação rural unifamiliar, provavelmente tipo quinta (Marques, 2011, p. 82-85). Este edifício teve pelo menos duas ocupações, uma que remonta ao século i a.C. e uma outra, mais tardia, que cessa provavelmente no final do século IV d.C. É possível que este edifício esteja acompanhado de outras estruturas, uma vez que os materiais romanos encontrados à superfície estendem-se por outras áreas da estação arqueológica. Mas por agora torna-se difícil avançar mais do que a correlação deste local como um espaço rural romano de carácter unifamiliar, 
que uma vez mais será abandonado no fim do Império. Pelos dados disponíveis, para já, constata-se um hiato de ocupação neste sítio entre o final do Império e o século $\mathrm{x}$, altura em que existiu, próximo do estabelecimento romano, um povoado e uma necrópole rupestre.

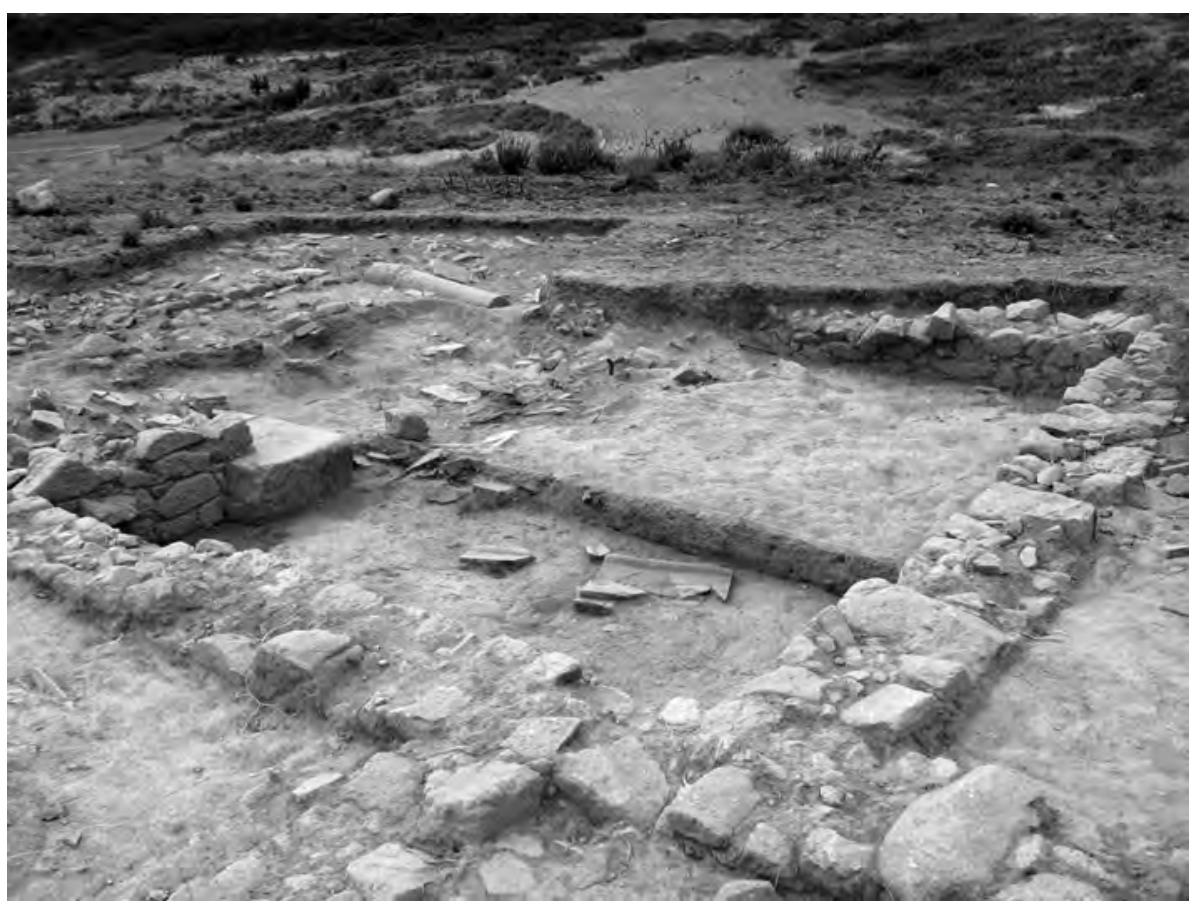

Figura 5 - Vista parcial da casa identificada no sector 9 de S. Gens (Celorico da Beira), cuja ocupação se baliza entre o século i a.C e o IV d.C.

Também na atual aldeia de Algodres (Fornos de Algodres) se efectuaram escavações recentes no âmbito de obras de remodelação urbana (Soares, Cardoso, 2004; Pinto, 2008). No espaço em redor da igreja da aldeia foram identificados contextos domésticos tardo-romanos e a necrópole medieval e moderna. $\mathrm{O}$ estudo preliminar do espólio permitiu evidenciar, uma vez mais, um hiato na ocupação que ocorre, precisamente, entre os séculos v e XI/XII, altura em que se terão ali iniciado os enterramentos ligados à igreja paroquial (Pereira, s.d.). O abandono de sítios romanos a partir do século III d.C. está ainda documentado em outros locais intervencionados no âmbito dos planos de minimização do alargamento da EN 221 e da construção da A25, como a Quinta da Pega I e a Quinta do Piroco (Apud Marques, 2011, p. 89-91). O primeiro, que correspondendo provavelmente a uma quinta, teve ocupação entre os séculos I ou II d.C. e o final do século iv ou início do v. Na Quinta do Piroco identificaram-se igualmente 
estruturas domésticas e rústicas consentâneas de uma ocupação rural tipo quinta cuja ocupação se balizou entre os séculos I e III d. C.

Sobre o destino dos sítios romanos após o fim do Império pouco se pode mais avançar, mas os dados disponíveis dos sítios arqueologicamente intervencionados indicam que os mesmos foram abandonados a partir do século III, com maior incidência em finais do Iv/inícios do v. Em alguns casos a ocupação humana é retomada nestes locais, mas após hiatos de tempo relativamente longos como ocorre no Monte Aljão, em S. Gens e em Algodres (fig. 5). Não há, por isso, para já, evidências de continuidade ocupacional entre os sítios imperiais e os alto-medievais. Muitas hipóteses se poderiam levantar face a estes dados, contudo, trata-se de informação muito escassa, o que tornaria uma eventual explicação pouco credível.

\begin{tabular}{|c|c|c|c|c|c|c|c|}
\hline Mte. Aljăo & -Wk-27458 & 1 & $m+1$ & 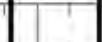 & 1 & $T$ & 17 \\
\hline Mte. Aljäo & -Wk-27457 & & & 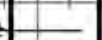 & & & \\
\hline Mte. Aljäo & $-W_{k}-25176$ & & 1 & if & & & \\
\hline Mte. Aljäo & -Wk-27459 & & & & 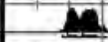 & & \\
\hline S. Gens - & Wk-27456 & & M & & & & \\
\hline S. Gens - & Wk-25175 & & & & & & \\
\hline S. Gens - & $W k-27455$ & & & & & & \\
\hline Soida-Wh & $k-25174$ & & & & - & & \\
\hline Soida - Wh & $k-27454$ & & & & & & \\
\hline Soida-Wh & $k-20462$ & & & & & & \\
\hline P. Mouros & $-W k-25818$ & & & & & & \\
\hline P. Mouros & - Sac-1947 & & & 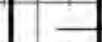 & & & \\
\hline P. Mouros & - Sac- 1950 & & & & & & \\
\hline A. Quintin & ha-Sac-2333 & & & 5 & & & \\
\hline Algodres - & Sac-2207 & & & & & i. & 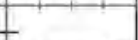 \\
\hline
\end{tabular}

Calibrated Date

Figura 6 - Gráfico com as datações C14 efectuadas nos sítios com ocupação da Alta Idade Média, com indicação do hiato ocupacional identificado entre os séculos IV/v e o século IX (Tente, 2010, sobre a discussão das várias datações consultar ainda Tente e Carvalho, 2011).

É, porém, de mencionar que muitos outros sítios se encontram referenciados pela prospeção e que em alguns deles há uma correlação espacial entre sepulturas escavadas na rocha - que como se sabe, podem ter sido construídas entre os séculos VI a XI (Tente 2010) - e vestígios consentâneos de vivências quotidianas. Sem escavações é impossível aferir a natureza desta proximidade espacial e se 
a mesma poderá corresponder a uma coincidência temporal. No entanto, não se pode descurar a possibilidade de em alguns destes casos poder ter existido efectivamente uma continuidade na ocupação. $O$ futuro da investigação abrirá certamente novos caminhos e novas interpretações.

Em terras mais a Norte, situadas já na Bacia do rio Douro é, aliás, defendida esta mesma continuidade, por exemplo nas villae do Prazo (Freixo Numão) e da Ervamoira (Muxagata). Mas nestes casos a publicação dos resultados (a título de exemplo Coixão, 1999; Guimarães, 2000) dos trabalhos arqueológicos realizados é ainda muito insuficiente e, por isso, levanta vários problemas de compreensão relativamente aos contextos de transição. No caso concreto do Prazo é proposto haver uma continuidade de ocupação até ao século VI, mas não se compreende o que ocorre após aquela centúria e se há, ou não, um abandono e uma posterior reocupação bem patente na necrópole ali identificada e claramente datável entre os séculos X e XII.

\section{Os sÉculos VI E VII}

Um dos documentos mais importantes para o conhecimento da organização episcopal sueva, o Parrochiale Suevum (572-579), tem sido entendido como reflexo da capacidade fiscal e governativa do reino suevo (Mattoso, 1985a). O documento seria um "testimonio de iglesias (o incluso territorios) que competen a la administración y la directa jurisdicción de la diocese episcopal' (Diáz, 1998, p. 40), pelo que estavam excluídas as igrejas de carácter privado e as monásticas, cujo número e implantação desconhecemos. Muitas das dioceses e paróquias mencionadas no documento são também referidas em outra documentação eclesiástica, como os Concílios, o que atesta a sua existência e funcionamento durante determinados períodos de tempo. O mapa de implantação das estruturas religiosas mencionadas apresenta uma maior concentração de referências junto do eixo Tui/Braga/ Porto, o que parece reflectir que era aí que a monarquia e a estrutura eclesiástica sueva tinha maior implantação. Fora deste eixo as referências são mais espaçadas e à medida que a distância aumenta, diminuem as menções, existindo espaços totalmente em branco. É o que sucede com o Alto Mondego.

As dioceses mais próximas do território em análise, referidas no Parrochiale, são as na dependência da diocese de Viseu. A arqueologia em Viseu não tem dado a conhecer informação relativa a este período histórico. A publicação da "basílica" de Viseu (Vaz, 2000) não é esclarecedora quanto às características e cronologia do edifício ali escavado, uma vez que sumariamente se publica o contexto sem o associar ao estudo dos materiais arqueológicos ali recolhidos. $\mathrm{Na}$ dependência desta diocese deveriam estar uma ou duas paróquias, que se poderiam situar no vale do Mondego. Noutro local foi sugerido que a paróquia de Suberbeno pudesse corresponder a algum dos sítios arqueológicos tardo-romanos/alto medievais existentes entre Seia e Gouveia (Tente, 2007). Também J. Mattoso avança com 
a hipótese da paróquia de Osania poder corresponder a Seia (1986/87). Todavia, para além de se tratar de meras hipóteses de trabalho, ambas propõem uma localização no extremo ocidente do território do Alto Mondego, deixando em branco o espaço entre a Guarda e Gouveia. A Norte conhece-se igualmente a paróquia viseense de Caliabria (Almendra, Vila Nova de Foz Côa), que entre 633 e 693 adquire o estatuto de diocese (Vives, 1963). Junto desta, e talvez na sua dependência durante o período diocesano, estaria a paróquia de Coleia, que Almeida Fernandes (1968) chegou a propor poder situar-se em Gouveia, mas cuja identificação da inscrição relativa à Civitas Cobelcorum em Torre de Almofala (Figueira de Castelo Rodrigo) veio comprovar não só o estatuto daquele local à época romana, como relacionar essa civitas com a paróquia sueva. A arqueologia desta região tem dado a conhecer alguns edifícios de carácter religioso que remontam a este período. Refira-se os já mencionados edifícios do Prazo e da Ervamoira. As referências a paróquias e a dioceses, onde se chegou a cunhar moeda, bem como o aparecimento de importantes vestígios arqueológicos na região do Côa, mostram que neste território emergiram elites que teriam ligações ao poder central (Martín Viso, 2008 e 2011), pelo menos em determinado momento, o que pode explicar, entre outras coisas, a ascensão de Caliabria a sede episcopal durante 60 anos.

A imagem que se pode traçar do Alto Mondego na mesma época é muito diferente. Não se conhecem paróquias, nem sedes episcopais, nem edifícios religiosos. Todavia, há algumas informações que remetem para estas cronologias e que permitem esboçar alguns traços do que seria este território durante o período de vigência política das monarquias sueva e visigoda.

Para além da inscrição funerária da Igreja de Santa Maria de Açores, datada de 666, conhecem-se ainda vários achados de moedas de ouro cunhadas durante o período visigodo: duas do Castro do Tintinolho (Cavadoude, Guarda); duas da área da actual cidade da Guarda; e uma outra em Ademoura (fig. 7), também no actual concelho da Guarda. I. Martín Viso (2008 e 2011) revê a informação relativa às tremisses encontrados no Nordeste da Lusitânia e relaciona-as com a presença de eventuais potentes, cujo poder assentaria na capacidade de cobrança fiscal.

Os locais de habitação desta elite não são fáceis de determinar por não existirem, para já, mais elementos de prestígio que possam identificá-los, situação aliás que se multiplica em várias áreas geográficas para este período, nomeadamente na região de Salamanca (Martín Viso, 2009). O Castro do Tintinolho (fig. 8) seria um destes sítios de altura onde se poderia ter promovido a "adaeratio". Os dados disponíveis apontam para um local cuja origem não está definida, mas que é dotado de um sistema defensivo durante os séculos vi e viI (Tente e Martín Viso, 2012). A sua implantação marca a paisagem da Bacia de Celorico, como nenhum outro sítio antropizado o faz naquela região. É um local para ser avistado e marcar o seu território. A referência ao achamento de duas moedas de ouro, cunhadas em Celo e Caesaraugusta nos reinados de Sisebuto e Suintila (Faria, 1985), permitem incluir este local no panorama das elites que estabeleceram, em 
certos momentos, relações com o poder central. A moeda de ouro, tal como assinalou I. Martín Viso $(2008,2011)$, não circularia, era antes um instrumento de poder criada para o sistema fiscal. O sistema da fiscalidade não é bem conhecido, mas percebe-se que o mesmo dependeria da capacidade de cobrança de impostos por parte dos potentes locais e da relação que estabelecem com o poder central. A moeda de ouro representaria essa relação fiscal. A sua identificação, neste contexto particular, não só atesta a presença dessas elites, como documenta a relação destas com a monarquia visigoda.

Em conjunto estes vestígios de prestígio de época visigoda atestam "que no eixo do vale, entre a actual barragem do Caldeirão e a aldeia de Açores, se encontraria uma elite local capaz de possuir moeda e de mandar esculpir inscriçôes funerárias. É esta elite que teria certamente no Castro do Tintinolho o seu simbolo mais marcante e a forma de facilmente se fazer representar naquele território" (Tente, Martín Viso, 2012, p. 69).

O sítio de Castelos Velhos (Guarda), que I. Martín Viso (2008) aponta como podendo ser um outro espaço de elites, tem de ser lido com atenção, pois a informação disponível é muito escassa para que se retirem conclusões sobre a funcionalidade e cronologia deste sítio já muito alterado pela expansão urbana.

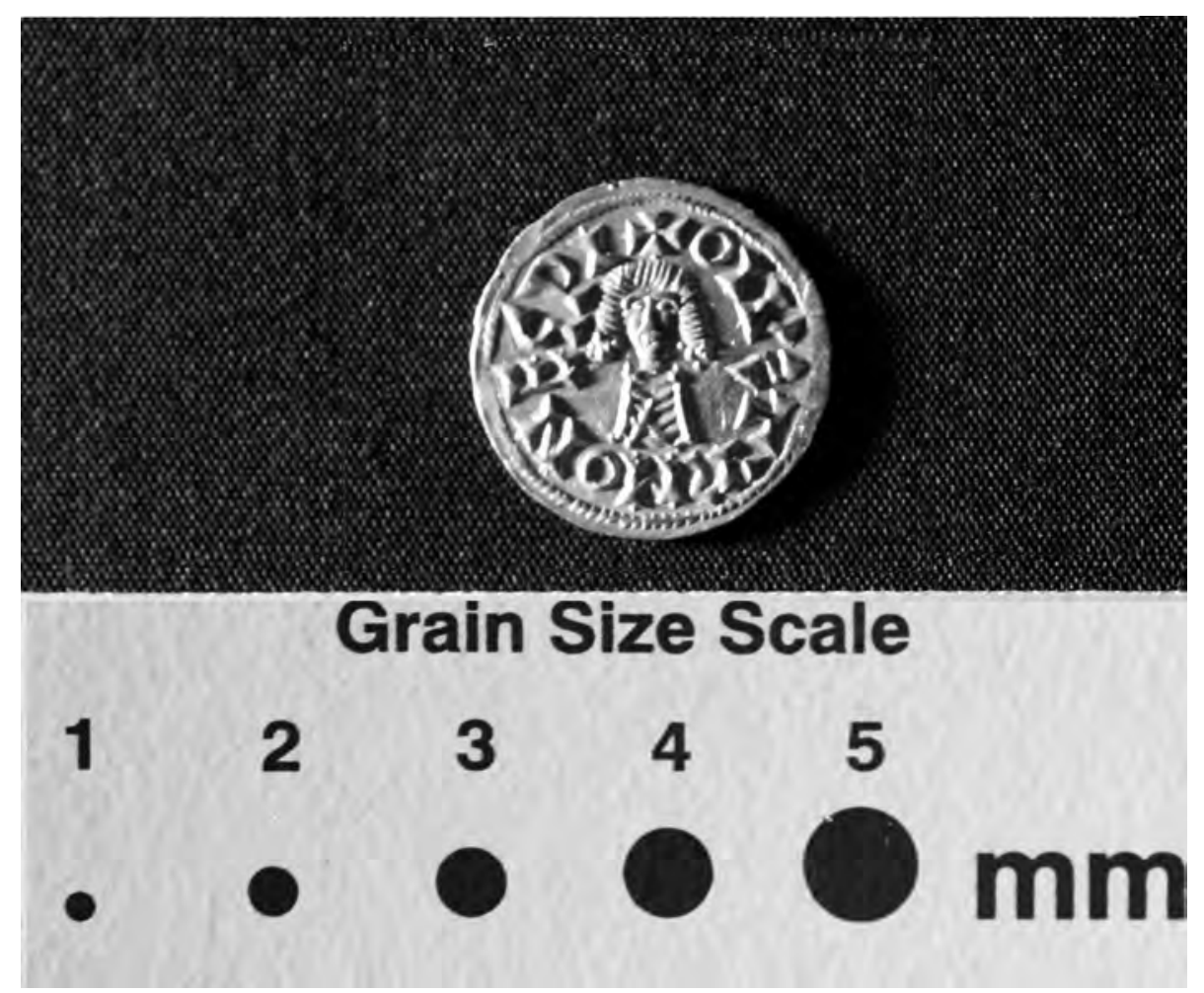

Figura 7 - Tremis de Recaredo cunhado em Monecipio proveniente de Ademoura. 


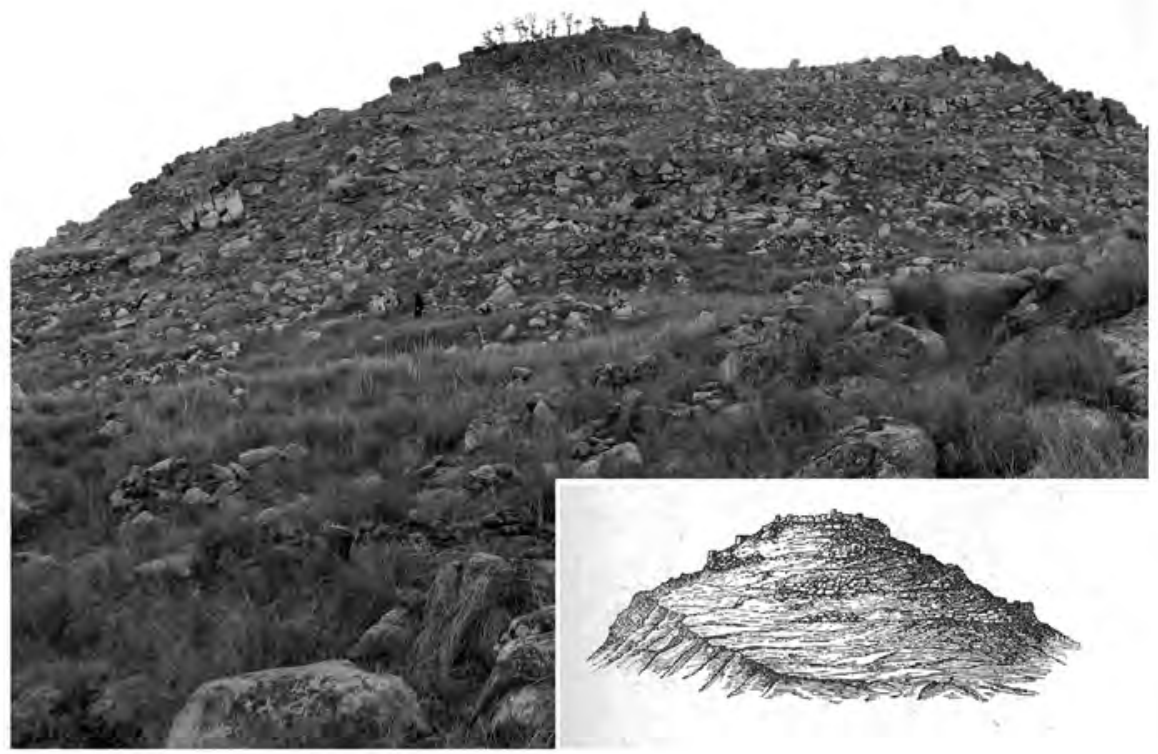

Figura 8 - Fotografia do Castro do Tintinolho e gravura de Martins Sarmento realizada durante a Expedição scientifica à Serra da Estrella em 1881 (Sarmento, 1883, Est II).

$\mathrm{Na}$ área mais ocidental do vale do Mondego está igualmente documentada a presença de gentes privilegiadas que viveram nestas centúrias. Na primeira metade do século XX foi encontrada na área do Freixial/Safail (Vila Nova de Tázem, Gouveia) uma pátera de bronze (fig. 9), cuja cronologia proposta por Russel Cortez (1950) aponta exactamente para os séculos VI/VII. A mesma apresenta a seguinte inscrição † ARGIMIRI VITA' DS 'VS ODI. A sua leitura não é consensual $^{1}$, mas vários autores relacionam a pátera a uma personagem de nome Argimiro, que para alguns seria um bispo viseense. Infelizmente tal antropónimo não aparece referido nas fontes documentais da época, nomeadamente entre os bispos daquela diocese referenciados nos concílios visigodos (Vives, 1963).

${ }^{1}$ Martins Sarmento em carta dirigida a Hübner datada de 15 de Fevereiro de 1899 interpreta como " $\dagger$ ARGIMIRI VI A(nno) P(ontificatu)SU(niversali)s [e]P(isco)pi"; Fidel Fita propõe a leitura "ARGIMIRI VITA AMOR SALUS POPULI"; Hubner por sua vez interpreta como “† ARGIMIRI VITAPS(ensis) VSP(rae) P(osit)I” ou “†ARGIMIRI VITA(li)S V(i)S(aeensis) (e)P(isco)PI “ (Apud Cortez, 1950, p. 61) e Russel Cortez lê “† ARGIMIRI VITA(m) D[EV] S (C)VS[T]ODI(T)” (Cortez, 1950, p. 66). 

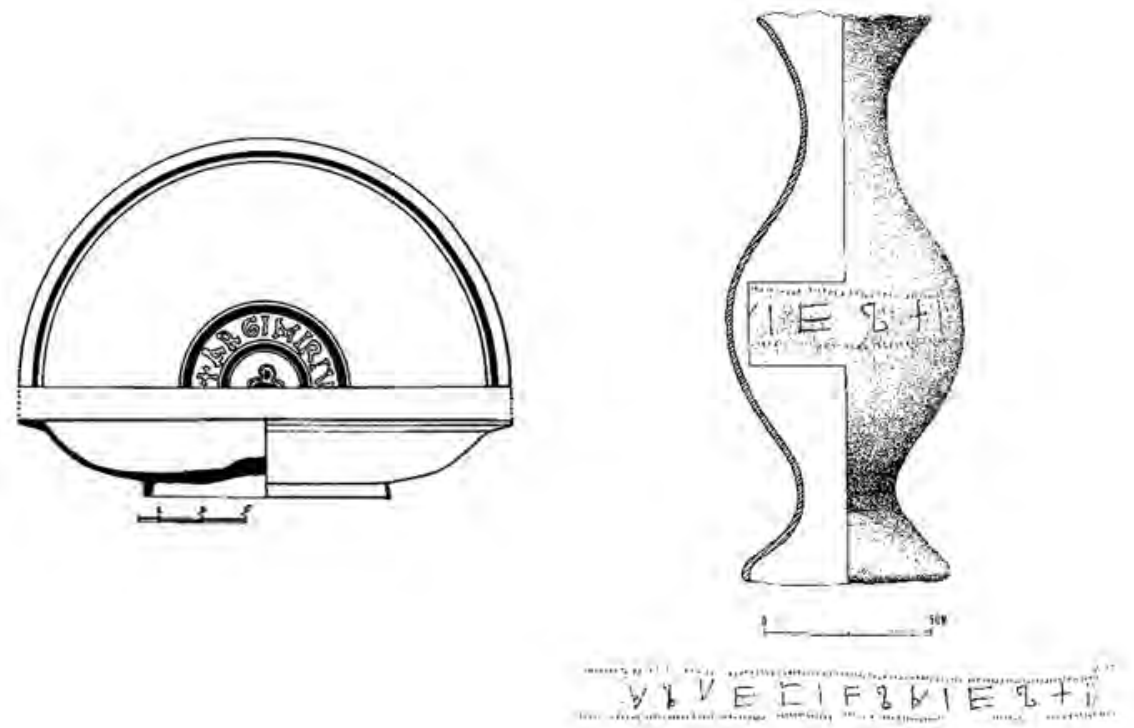

Figura 9 - Pátera do Safail publicada por Russel Cortez (1950) e Jarro da Bobadela publicado por M. Varela Gomes e M. Alves Dias (1995).

Um outro objecto litúrgico foi identificado por volta da mesma época na Bobadela. Trata-se do jarro em bronze (fig.9) com a seguinte inscrição incisa "ASAECLESAIES+I" 2(Gomes e Dias, 1995). Quanto à sua cronologia referem que "a forma pouco evolucionada do jarro de (sic) Bobadela que, como indicámos, ainda é próxima da dos seus protótipos importados, permite, para tal facto, que o datemos no terceiro quartel do século VII, ou seja no periodo correspondente ao reinado de Recesvinto" (idem, p. 97). Independentemente da validade desta datação tão precisa, a presença deste objecto litúrgico indicia uma vez mais a presença de elites com capacidade de consumo destes objectos de excepção, que, tal como a pátera, se podem relacionar com funções e/ou espaços religiosos.

Excluindo a possibilidade (que existe) de que algumas das sepulturas escavadas na rocha possam remontar aos séculos VI e viI, apenas se conhece mais um vestígio religioso do Alto Mondego. Trata-se da inscrição rupestre identificada na Bravoíssa (Melo, Gouveia), gravada num afloramento situado a meia encosta da serra (Tente e González López, 1998). É uma inscrição muito tosca, que demonstra uma fraca capacidade técnica. A sua leitura não é fácil, mas

${ }^{2}$ Que foi interpretada como "a S(ancta) Aecle[i]a Ies(u) Ch(rist)i" ou "a S(anct)a Ecle[i]a Ies(u) Ch (rist)i” (Gomes e Dias, 1995, p. 95). 
aparentemente está escrito $I \Delta^{\prime} \Omega I L u x^{3}$, o que claramente remete para o carácter religioso da mesma. Possivelmente este vestígio poderá inscrever-se num contexto das comunidades eremíticas paleocristãs. A densa vegetação existente na área da inscrição não possibilitou uma prospeção adequada que eventualmente pudesse identificar outros vestígios associados.

Concluindo, para o período dos séculos VI e VII os vestígios arqueológicos são muito escassos e apenas permitem vislumbrar a presença no território de potentes locais, alguns dos quais eventualmente ligados à estrutura religiosa de período suevo-visigodo. Contrariamente ao que ocorre para os séculos IX e $\mathrm{x}$, estão ausentes do registo arqueológico, até agora conhecido, a população não privilegiada. Tal pode dever-se à incapacidade de identificar no terreno traços da sua existência, por serem esses mesmos vestígios ainda mais invisíveis do que os que caracterizam as centúrias seguintes.

\section{Depois do século ViII E EM JeIto de ConClusÃo...}

Do século viII nada se sabe. Os parcos dados arqueológicos disponíveis parecem evidenciar um abandono de locais como o Castro do Tintinolho. No início do século $\mathrm{X}$, ou eventualmente ainda no século IX, o registo arqueológico documenta a fundação de novos sítios arqueológicos de carácter rural que agregam várias famílias (Tente, 2009, 2010). Estas instalam-se quer em locais nunca antes ocupados, como a Soida (Rapa, Celorico da Beira) ou o Penedo dos Mouros (Arcozelo da Serra, Gouveia), mas algumas escolhem espaços anteriormente habitados, tais como S. Gens e Monte Aljão. Algo de extraordinário terá ocorrido então para que nova alteração na estrutura do povoamento ocorra. Com a invasão muçulmana em 711, os potentes locais dos séculos vi e viI podem ter sido esvaziados do seu prestígio sociopolítico, porque este assentaria numa relação com a monarquia então extinta. Perante a falência ou o desaparecimento destes senhores a população reorganizar-se-ia, juntando-se em pequenas comunidades de várias famílias, que desenvolvem entre si laços de fidelidade e comunitarismo. Estas organizam o povoado onde habitam e o território que controlam, orientando as suas actividades económicas numa estratégia de subsistência, vocacionada fundamentalmente para a sobrevivência da comunidade. Estes novos sítios podem ser a expressão desta nova ordenação política e territorial. Seria assim a ausência de poder supra local e a instabilidade resultante do facto do Mondego ter sido terra de fronteira entre cristãos do Norte e muçulmanos do Sul, o motor para estas transformações que são levadas a cabo pelas próprias comunidades de camponeses. Efetivamente, para este período, ao contrário do que parece ocorrer

\footnotetext{
${ }^{3}$ Ler-se-ia “| Alfa Omega |Lux", ou seja o Princípio, o Fim, a Luz.
} 
para a fase anterior, não se vislumbra neste território a presença de gente social ou economicamente muito diferenciada.

Ao contrário do que ocorre em algumas outras áreas europeias, os dados disponíveis não habilitam a que se fale de uma continuidade do povoamento que remonte aos séculos IV e v, ou mesmo aos vi e viI. Os sítios datados do século $\mathrm{X}$ que foram escavados no Alto Mondego (Tente, 2010; Tente, 2011a; Tente e Carvalho, 2011) são abandonados no final do milénio, provavelmente em sequência da expansão do poder senhorial ligado à coroa astur-leonesa. Apenas no século XI se volta a rastrear a presença de poderes com expressão supra-local. A menção documental aos castelos de meia encosta da Serra da Estrela que, em meados desse século, estão a organizar de forma coordenada a defesa da região são disso indicador, mas aqui continua uma outra historia, já muito distante do fim do Império Romano. 


\section{BibLIOGRAFIA}

Alarcão, J. (2001): “Os nomes de algumas povoações da parte portuguesa da Lusitânia”, Sociedad y Cultura em Lusitania Romana (IV Mesa Redonda Internacional), Mérida, p. 165-172.

Alarcão, J. (2007) - Ainda sobre a localização dos povos referidos na inscrição da Ponte de Alcântara. In Lusitanos e romanos no Nordeste da Lusitânia. Actas das 2as Jornadas da Beira Interior. Guarda. Centro de Estudos Ibéricos, p. $119-132$.

Barroca. M. J. (1992): A inscrição de Sta. Maria de Açores (666). Nova leitura, Revista da Faculdade de Letras. História, 2. a série, vol. Ix, Porto, p. 507-516.

Carvalho,Pedro C. (2005) - Identificação e representação espacial das capitais de civitates da Beira Interior, In Actas das 2as Jornadas de Património da Beira Interior: Lusitanos e Romanos no Nordeste da Lusitânia, CEI/ARA, Guarda, p. 155-169.

Carvalho, P. (2008) - Por terras do Sabugal em época romana. In Museu do Sabugal. Coleç̧ão arqueológica. Câmara Municipal do Sabugal, p. 72-83.

Carvalho, P. (2009) - Há 2000 anos em Celorico da Beira. Entre as encostas da Estrela e o vale do Mondego ao tempo dos Romanos. In Celorico através da Historia. Celorico da Beira, p. 31-49.

Coelho, M. H. C., Pimenta, M. C. (2009) - Celorico Medieval. um cruzamento de Homens e Bens na Paz e na Guerra, In Celorico através da Historia. Celorico da Beira, p. 68-88.

Coixão, A. N. S. (1999) - Rituais e Cultos da Morte na Região de Entre Douro e Côa. [s.1.]. Associação Cultural Desportiva e Recreativa de Freixo Numão.

Cortez, F. Russel (1950) - Objectos de Liturgia Visigótica encontrados em Portugal. Séculos v a viI. In O Instituto. Coimbra. 114, p. 52-92.

Daveau, S. (1969) - Struture et Relief de la Serra da Estrela. Finisterra, IV :7-8, p. 31-63 e p. 159- 197.

Diáz, P. (1998) - El parrochiale suevum: organización eclesiástica, poder político y poblamiento en la Gallecia Tardoantiqua. In ALVAR, J. (Ed.) - Homenaje a José $M^{a}$ Blázquez. Vol. VI - Antigüedad: religiones y sociedades. Madrid, p. 35-47.

Faria, A. M. (1985) - Subsídios para um inventário dos achados monetários no distrito da Guarda, Separata de Bibliotecas Arquivos e Museus, Instituto Português do Património Cultural, Lisboa.

Ferreira, A. de B. (1978) - Planaltos e Montanhas do Norte da Beira. Lisboa: Centro de Estudos Geográficos (Memórias do Centro de Estudos Geográficos; 4). 
Ferreira, M. C, Osório, M., Perestelo, M.S. (2004) - Ara votiva a Amma de Vale de Azares, Ficheiro Epigráfico. 77. n. ${ }^{\circ}$ 347. Coimbra, 2004.

Gomes, M. V.; Dias, M. M. A. (1995) - Jarro litúrgico, visigótico, de Bobadela (Coimbra). In IV Reunião de Arqueologia Cristã Hispânica, Barcelona, p. 91-98.

Guimarães, G. (2000) - Vestígios paleocristãos de Ervamoira, Vale do Côa. In III Congresso de Arqueologia Peninsular. Vol. VI. Porto, p. 617-631.

Machado,J.P. (1991) - Vocabulário português de origem árabe. Lisboa. Ed. Notícias.

Marques, A. C. (2011) - A Ocupação Romana na Bacia de Celorico. Dissertação de mestrado apresentada à Faculdade de Letras da Universidade de Coimbra, Coimbra: policopiado.

Marques, A. C.; Lobão, J. C.; Carvalho, P. (2012) - Ara a Júpiter de Açores (Celorico da Beira) (Conventus Emeritensis), Ficheiro Epigráfico, 103-456, Coimbra: FLUC.

Martín Viso, I. (2008) - Tremisses y potentes en el Nordeste de Lusitania (siglos VI-VII), Melanges de la Casa Velázquez 38-1, p. 175-200.

Martín Viso, I. (2009) - Espacios sin Estado. Los territorios occidentales entre el Duero y el Sistema Central (siglos viII-IX), In Martín Viso, I., ed., ¿̨ Tiempos oscuros? Territorio y sociedad en el centro de la Península Ibérica (siglos $V I I-X)$, Madrid: Silex, p. 107-135.

Martín Viso, I. (2011) - Circuits of power in a fragmented space: gold coinage in the Meseta del Duero (sixth-seventh centuries), Escalona, J. y Reynolds, A., eds., Scale and scale change in the early middle ages. Exploring landscape, local society and the worls beyond, Turnhout, p. 215-252.

Mattoso, J. (1985) - A história das paróquias em Portugal. In Portugal Medieval: Novas interpretaçôes. Lisboa. INCM, p. 37-56.

Mattoso, J. (1986/87) - Seia na Idade das Trevas. Seia. Câmara Municipal de Seia.

Neto, M. S. (2009) - Celorico da Beira na época moderna, In Celorico através da Historia. Celorico da Beira, p. 90-107.

Pereira, T. (S.D.) - A cultura material da aldeia de Algodres entre a Antiguidade Tardia e a Alta Idade Média, Iberografias, n. ${ }^{\circ}$ 9, Guarda: CEI, no prelo.

Pereira, V. (2005) - Intervenção Arqueológica na Póvoa do Mileu (Guarda), In Actas das 2. as Jornadas de Património da Beira Interior: Lusitanos e Romanos no Nordeste da Lusitânia, Guarda: CEI / ARA, p. 229-248.

Pereira, V. (2008) - A Romanização da Região da Guarda, In Roteiro Arqueológico da Guarda, Território, Paisagens e Artefactos, Guarda: Câmara Municipal da Guarda. 
Perestrelo, M. S. G. (2003) - A romanização na Bacia do Rio Côa, Ministério da Cultura - Parque Arqueológico do Vale do Côa.

Pinto, M.A (2008) - Intervenção Arqueológica no âmbito da Empreitada de Melhoramentos do centro Histórico de Algodres - Relatório dos Trabalbos Arqueológicos. ERA-Arqueologia S.A. Policopiado.

Sarmento, F. M. (1883) - Expedição scientifica à Serra da Estrella em 1881. Secção de Archeolgia. Relatório. Lisboa. Imprensa Nacional.

Soares, A. e Cardoso, H. (2004) - Algodres, Intervenção arqueológica de emergência. Relatório final, entregue ao IPA, processo n. ${ }^{\circ}$ S-7640. Policopiado.

Tente, C. (2007) - A ocupação alto-medieval da Encosta Noroeste da Serra da Estrela. Lisboa, IPA. Trabalhos de Arqueologia: 47.

Tente, C. (2009) - "Viver em autarcia. O Alto Mondego entre os séculos v e xI". In Martín Viso, I. - $\dot{i}$ Tiempos oscuros? Territorio y sociedad en el centro de la Peninsula Ibérica (siglos VI-X). Salamanca: p. 137-157.

Tente, C. (2010) - Arqueologia Medieval Cristã no Alto Mondego, Ocupação e exploração do território nos séculos $V$ a XI, dissertação de doutoramento apresentada à Universidade Nova de Lisboa, Lisboa: policopiado.

Tente, C. (2011) - Do séculos IX ao Xi no Alto Vale do Mondego (Guarda, Portugal): Dinâmicas de povoamento e estruturas sociais. Debates de Arqueologia Medieval. Granada, p. 23-43. Revista on-line disponível em www. arqueologiamedievaldebates.com

Tente, C.; Carvalho, A. F. (2011) - The establishment of radiocarbon chronologies for early medieval sites: a case study from the upper Mondego Valley (Guarda, Portugal). Munibe, 62. UPV, p. 461-468.

Tente, C. e Gonzàlez López, M. (1998) - A inscrição rupestre da freguesia de Melo (Gouveia) - notícia preliminar. Trabalhos de Arqueologia da E.A M. Lisboa. Edições Colibri. 3|4, p. 293-297.

Tente, C., Martín Viso, I. (2012) - O Castro do Tintinolho (Guarda, Portugal). Interpretação dos dados arqueológicos como fortificação do período pós-romano, In: Quirós Castillo, J. A., Tejado Sebastián (Eds.) - Los Castillos Altomedievales en el Noroeste de la Peninsula Ibérica, UPV, p.57-75.

Ventura, L.e Faria, A. S. et all (1990) - Livro Santo de Santa Cruz, Coimbra, INIC.

Vives, J., Ed. (1963) - Concilios Visigóticos e Hispano-Romanos. CSIC. Instituto Enrique Florez. Madrid. 